\title{
OOROTASIOHO
}

Available online at Website http://ejournal.undip.ac.id/index.php/rotasi

\section{DESAIN DAN PEMODELAN HUMANOID ROBOT}

\author{
*Munadi, Beni Anggoro \\ Jurusan Teknik Mesin, Fakultas Teknik, Universitas Diponegoro \\ Jl. Prof. Sudharto, SH, Tembalang, Semarang 50275 \\ *E-mail: munadi@undip.ac.id
}

\begin{abstract}
ABSTRAK
Artikel ini memaparkan tahapan dalam mendesain kontruksi mekanik humanoid robot yang sederhana. Desain sebagai tahapan awal dalam pembuatan humanoid robot sebelum dilakukan pemodelan kinematik dan pemodelan dinamik. Untuk pemodelan kinematik akan dilakukan analisa forward kinematics dengan menggunakan notasi parameter Denavit-Hartenberg (DH parameter). DH parameter menggunakan matrik homogeneous transformation $4 \mathrm{x} 4$ untuk menyatakan hubungan spasial antara dua link yang berhubungan, sehingga dengan matrik transformasi tiap link humanoid robot yang diperoleh dapat menyederhanakan masalah forward kinemtic. Pada pemodelan dinamik akan dilakukan analisa torsi pada joint ankle dengan menggunakan persamaan Lagrangian. Pemodelan dinamik diperoleh energi kinetik dan energi potensial yang terdapat pada tiap link humanoid robot, sehingga dari turunan persamaan Lagrangian diperoleh torsi pada joint ankle humanoid robot. Dalam pergerakan humanoid robot pada joint space mempunyai jalur lintasan (trajectory) sebagai fungsi trajectory terhadap waktu. Proses desain menggunakan alat bantu software SolidWorks dan untuk analisa perhitungan kinematik dan dinamik menggunakan software MATLAB.
\end{abstract}

Kata kunci: Humanoid robot, Kinematik, Dinamik, Lagrangian, MATLAB

\section{PENDAHULUAN}

Dewasa ini, perkembangan teknologi robot sangat cepat. Robot diciptakan dengan tujuan agar dapat membantu manusia untuk melakukan pekerjaan yang khususnya bersifat memerlukan kecepatan tinggi, memiliki resiko tinggi, kotor (kumuh) dan yang sifatnya berulang-ulang [1]. Model robot saat ini sangat bervariatif dari model mobile robot sampai dengan humanoid robot. Humanoid robot didesain agar mampu bergerak seperti layaknya seorang manusia serta dapat berpikir dan mengambil suatu keputusan berdasarkan logika-logika yang telah terprogram, karena itulah humanoid robot mendapat perhatian besar untuk dikembangkan. Selanjutnya beberapa perusahaan maupun institusi perguruan tinggi baik luar negeri maupun dalam negeri berlomba-lomba mengembangkan dan memproduksi humanoid robot dengan teknologi terkini.

Proses desain sampai dengan aplikasi humanoid robot tentunya memakan banyak biaya yang tidak murah dan waktu yang cukup lama untuk penelitian. Oleh karena itu, salah satu tujuan penilitian ini adalah mendesain kontruksi mekanik humanoid robot yang sederhana, murah, dan ringan, sehingga dapat digunakan untuk proses pembelajaran dalam lingkup perguruan tinggi, artinya masih terjangkau dalam hal biaya maupun waktu.

Pada penelitian ini akan dibahas tentang desain dan pemodelan kinematik dan dinamik humanoid robot yang merupakan tahapan awal dalam rantai bangun humanoid robot. Desain dan pemodelan kinematik humanoid robot ini difokuskan pada humanoid robot yang berukuran kecil yang kedepannya dapat diaplikasikan pada perlombaan Soccer Robot pada event Kontes Robot Indonesia (KRI) dan Kontes Robot Cerdas Indonesia (KRCI).

\section{KINEMATIKA DAN DINAMIKA ROBOT}

\subsection{Konsep Kinematika pada Robot}

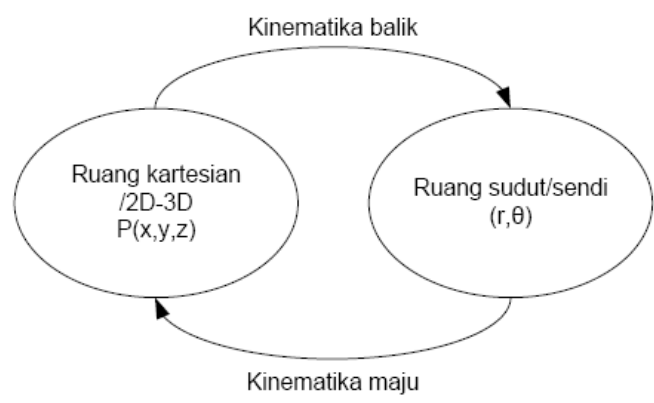

Gambar 1. Transformasi kinematik maju dan kinematik balik [2]
Berdasarkan Gambar 1 diperoleh informasi bahwa jari-jari $r$ dan $\theta$ dari suatu struktur robot n-DoF diketahui, maka posisi yang dinyatakan dengan $\mathrm{P}(\mathrm{x}, \mathrm{y}, \mathrm{z})$ dapat dihitung. Jika $\theta$ merupakan sebuah fungsi berdasarkan waktu $\theta(\mathrm{t})$, maka posisi dan orientasi $\mathrm{P}(\mathrm{t})$ dapat dihitung juga secara pasti. Transformasi koordinat ini dikenal sebagai kinematika maju. Selanjutnya jika posisi dan orientasi $\mathrm{P}(\mathrm{t})$ diketahui maka, $\theta(\mathrm{t})$ tidak langsung dapat dihitung tanpa mendefinisikan berapa DoF struktur robot itu. Jumlah sendi $n$ dari n-DoF yang dapat dibuat untuk melaksanakan tugas sesuai dengan posisi dan orientasi $\mathrm{P}(\mathrm{t})$ itu dapat bernilai $\mathrm{n}=(\mathrm{m}, \mathrm{m}+1$, $\mathrm{m}+2, \ldots, \mathrm{m}+\mathrm{p}$ ) dimana $\mathrm{m}$ adalah jumlah sendi minimum dan $\mathrm{p}$ adalah jumlah sendi yang dapat ditambahkan. Transformasi ini dikenal sebagai kinematika balik.

Kinematika robot adalah studi analitis pergerakan kaki atau lengan robot terhadap sistem kerangka koordinat acuan yang diam/bergerak tanpa memperhatikan gaya yang menyebabkan pergerakan tersebut. Model kinematika 
merepresentasikan hubungan end effector dalam ruang tiga dimensi dengan variabel sendi (joint) dalam ruang sendi. Pemodelan kinematik ini diklasifikasikan ke dalam kinematik maju (forward kinematic) dan kinematik balik (inverse kinemtic). Kinematika maju mendeskripsikan posisi dan orientasi end effector yang dinyatakan dalam posisi sendi, sedangkan kinematika balik mendeskripsikan konfigurasi posisi sendi untuk menghasilkan posisi dan orientasi end effector tertentu. Untuk lebih jelasnya dapat dilihat pada Gambar 1.

\subsection{Denavit-Hertenberg (DH) Parameter}

Denavit dan Hartenberg memperkenalkan pendekatan sistematik dan pendekatan umum menggunakan matriks algebra untuk menyatakan dan menunjukkan geometri spasial pada link pada lengan robot dengan frame yang tetap. DH parameter ini menggunakan matriks homogeneous transformation 4 x 4 untuk menyatakan hubungan spasial antara dua link yang berhubungan serta menyederhanakan masalah forward kinematics pada matriks transformasi homogeneous yang berhubungan dengan penempatan spasial dari frame koordinat lengan terhadap frame koordinat referensi. Matriks transformasi homogeneous dinyatakan dengan matrik transformasi $\mathrm{T}$ pada sendi ke- $i$ adalah seperti yang terlihat pada persamaan di bawah ini:

$$
{ }^{\mathrm{i}-1} \mathbf{T}_{\mathrm{i}}=\left[\begin{array}{cccc}
\cos \theta_{i} & -\sin \theta_{i} & 0 & a_{i-1} \\
\sin \theta_{i} \cos a_{i-1} & \cos \theta_{i} \sin a_{i-1} & -\sin a_{i-1} & -d_{i} \sin a_{i-1} \\
\sin \theta_{i} \sin a_{i-1} & \cos \theta_{i} \sin a_{i-1} & \cos a_{i-1} & d_{i} \cos a_{i-1} \\
0 & 0 & 0 & 1
\end{array}\right]
$$

\subsection{Persamaan Dinamik}

Dalam menganalisa pergerakanan dinamik pada humanoid robot menggunakan persamaan Lagrangian yang merupakan selisih dari energi kinetik dan energi potensial. Penurunan model Lagrangian dimulai dengan memperkenalkan prinsip-prinsip dalam menghitung torsi yang bekerja pada aktuator humanoid robot dengan menggunakan pertimbangan energi. Dengan menggunakan penurunan kinematik, koordinat sudut servomotor dan posisi yang dibutuhkan dapat diketahui. Dengan posisi dan kecepatan yang diketahui, energi-energi yang bekerja pada joint robot dapat ditentukan.

Persamaan Lagrangian didasarkan dengan pertimbangan pada energi kinetik (EP) dan energi potensial (EP) dalam sistem mekanisnya. Sebuah sistem mekanis dengan $n$ derajat kebebasan dapat digambarkan dengan $n$ koordinat umum, dilambangkan $q_{1} \ldots q_{n}$. Ketika sistem tersebut bergerak dari waktu A ke waktu B, prinsip Hamilton's menyatakan bahwa perbedaan energi kinetik dan energi potensial adalah minimal. Ini berarti bahwa integral berikut ini memiliki nilai yang penting, dimana $I$ adalah minimal.

$$
I(q, \dot{q})=\int_{A}^{B} L(t, q, \dot{q}) d t
$$

dimana I adalah fungsi yang didefinisikan pada suatu kurva dengan nilai sebenarnya. L = EK- EP disebut Lagrangian, $\mathrm{t}$ adalah waktu, dan $q$ adalah koordinat umum. Kondisi yang diperlukan untuk integral untuk menjadi minimal disebut dengan persamaan Euler-Lagrangian, yaitu:

$$
\frac{d}{d t} \frac{\partial L}{\partial \dot{q}}-\frac{\partial L}{\partial q}=0
$$

Gaya dari luar $Q$ dapat dihitung dengan menggunakan prinsip Lagrange-d'Alembert, yaitu:

$$
\frac{d}{d t} \frac{\partial L}{\partial \dot{q}}-\frac{\partial L}{\partial q}=Q
$$

Sudut servomotor $\theta$ akan digunakan sebagai koordinat umum yang akan menghasilkan perhitungan sederhana. Hal ini juga mengubah gaya eksternal ke torsi yang dihasilkan dari gerakan dan gravitasi pada sistem. Gesekan pada sendi dan gaya dorongan udara akan diabaikan serta gaya pegas dari kabel juga diabaikan. Dengan demikian persamaanya yaitu:

dimana $\tau$ adalah torsi aktuator [3].

$$
\frac{d}{d t} \frac{\partial L}{\partial \dot{\theta}}-\frac{\partial L}{\partial \theta}=\tau
$$

\subsection{Trajectory Generation}

Dalam pergerakan humanoid robot pada joint space mempunyai jalur lintasan (trajecotry) sebagai fungsi trajectory terhadap waktu. Trajectory mengacu pada posisi sudut $(\theta)$ dan kecepatan sudut $(\dot{\theta})$ terhadap waktu dari setiap joint. Trajectory pada penelitian ini dinyatakan dengan fungsi polynomial orde tiga sebagai berikut:

$$
\theta(\mathrm{t})=a_{0}+a_{1} \mathrm{t}+a_{2} \mathrm{t}^{2}+a_{3} \mathrm{t}^{3}
$$




$$
\dot{\theta}(\mathrm{t})=a_{1}+2 a_{2} \mathrm{t}+3 a_{3} \mathrm{t}^{2}
$$

Selanjutnya dengan kondisi batas $\theta(0)=0$ dan $\dot{\theta}(\mathrm{t} f)=0$ diperoleh nilai:

$$
a_{0}=\theta_{0} ; a_{1}=0 ; a_{2}=\frac{3}{t f^{2}}\left(\theta_{f}-\theta_{0}\right) ; \operatorname{dan} a_{3}=-\frac{3}{t f^{3}}\left(\theta_{f}-\theta_{0}\right)
$$

Sehingga didapat persamaan untuk trajectory sebagai berikut:

$$
\theta(\mathrm{t})=\theta_{0}+\frac{3}{t f^{2}}\left(\theta_{f}-\theta_{0}\right) \mathrm{t}^{2}-\frac{3}{t f^{3}}\left(\theta_{f}-\theta_{0}\right) \mathrm{t}^{3} \quad \dot{\theta}(\mathrm{t})=\frac{6}{t f^{2}}\left(\theta_{f}-\theta_{0}\right) \mathrm{t}-\frac{6}{t f^{3}}\left(\theta_{f}-\theta_{0}\right) \mathrm{t}^{2}
$$

dimana $\theta_{0}$ adalah sudut awal, $\theta_{f}$ sudut akhir, dan $\mathrm{t}_{\mathrm{f}}$ waktu akhir [4].

\section{PEMODELAN HUMANOID ROBOT}

\subsection{Desain Humanoid Robot}

Desain humanoid robot menggunakan software SolidWorks. Hal ini dilakukan agar dalam melakukan pembuatannya dapat mengurangi kesalahan pada gambar, misalnya dimensi. Dengan software SolidWorks maka kita dapat milihat suatu benda dengan gambaran utuh atau perbagian dengan sudut pandang yang jelas dan dapat diatur dengan sudut pandang isometric. Desain humanoid robot ini dibatasi tinggi sebesar $350 \mathrm{~mm}$ dan memiliki 19 degrees of freedom (DoF) dengan akuatornya adalah servomotor. Derajat kebebasan atau degree of freedom (DoF) merupakan jumlah variabel maksimum yang dibutuhkan untuk mendefenisikan gerak suatu benda. Gerakan manipulator dihasilkan dari adanya sendi (joint). Dalam desain humanoid robot ini, persendianya menggunakan revolute joint yang dapat berputar ke sumbu longitudinal (roll), sumbu lateral (pitch) atau sumbu vertikal (yaw). Lebih jelasnya, desain humanoid robot ditunjukan pada Gambar 2, dan penjelasannya pada Tabel 1 dan Tabel 2.

Tabel 1. Keterangan desain humanoid robot.

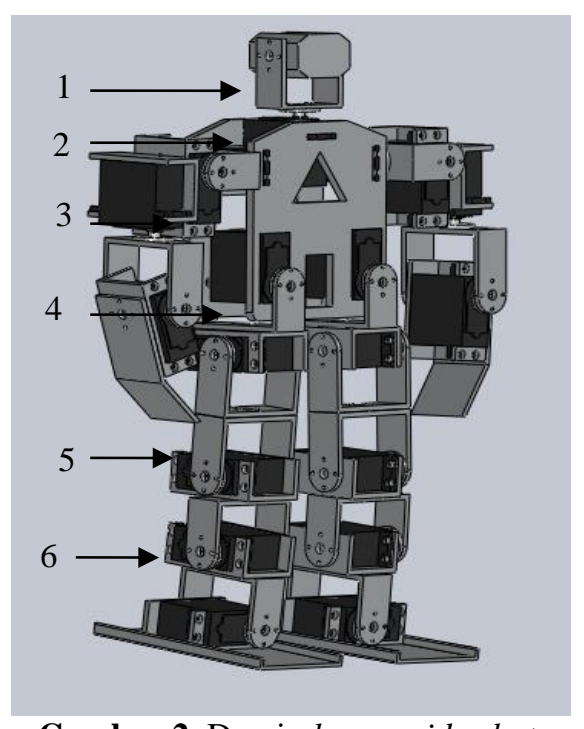

Gambar 2. Desain humanoid robot.

\begin{tabular}{|c|c|c|}
\hline No & Item sp & fikasi \\
\hline 1 & Tinggi & : $\quad 350 \mathrm{~mm}$ \\
\hline 2 & Berat & $: 2.840 \mathrm{gr}$ \\
\hline 3 & Degree of Freedom (DoF) & \\
\hline & $\begin{array}{ll}\text { - } & \text { Kaki } \\
\text { - } & \text { Tangan } \\
\text { - } & \text { Kepala } \\
\text { - } & \text { Total }\end{array}$ & $\begin{array}{l}: 5 \times 2=10 \\
: \quad 4 \times 2=8 \\
: \quad 1 \times 1=1 \\
: \quad 19 \text { DoF }\end{array}$ \\
\hline 4 & Aktuator joint & : $\quad$ Servomotor \\
\hline 5 & Material link & : $\quad$ Almunium \\
\hline
\end{tabular}

\begin{tabular}{|c|l|c|c|}
\hline No & \multicolumn{1}{|c|}{ Lokasi } & DoF & Keterangan \\
\hline \hline 1 & Kepala (Head) & 1 & Yaw \\
\hline 2 & Bahu (Shoulder) & $2 \times 2$ & Pitch + Roll \\
\hline 3 & Siku (Elbow) & $2 \times 2$ & Pitch + Yaw \\
\hline 4 & Pinggul (Hip) & $2 \times 2$ & Pitch + Roll \\
\hline 5 & Lutut (Knee) & $2 \times 1$ & Pitch \\
\hline 6 & $\begin{array}{l}\text { Pergelangan } \\
\text { kaki (Ankle) }\end{array}$ & $2 \times 2$ & Pitch + Roll \\
\hline
\end{tabular}

Tabel 2. Spesifikasi desain humanoid robot.

\subsection{Pemodelan Kinematik}

Ada tiga tahapan untuk menentukan model kinematik pada robot, yaitu langkah pertama menentukan frames link robot, langkah kedua mengindifikasi 4 link parameter pada setiap link robot, dan yang ketiga menemukan hubungan matrik transformasi. Untuk menentukan frames robot pada humanoid robot, dapat dilihat pada Gambar 3 dan 4 . Pada gambar, kaki kanan (Right Leg) disingkat dengan RL, kaki kiri (Left Leg) disingkat dengan LL, tangan kanan (Right Arm) disingkat dengan RA, dan tangan kiri (Left Arm) disingkat dengan LA. RL1 menunjukan joint pertama pada kaki kanan robot. LL1 menunjukan joint pertama pada kaki kiri robot. RA1 menunjukan joint pertama pada tangan kanan robot. LA1 menunjukan joint pertama pada tangan kiri robot. 


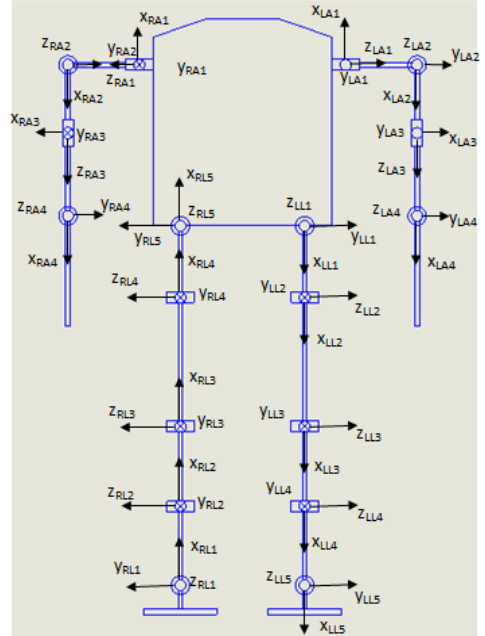

Gambar 3. Frames humanoid robot.

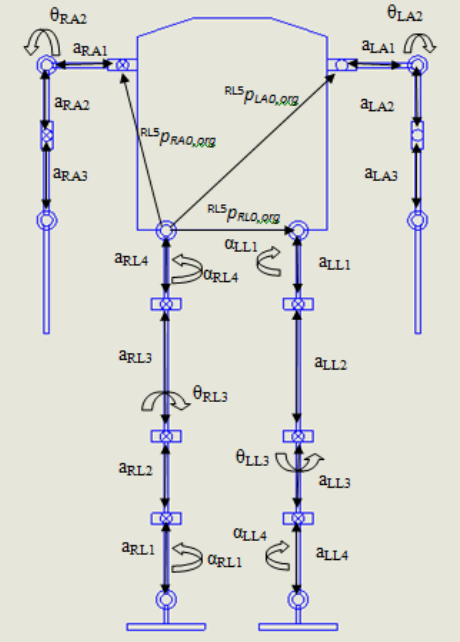

Gambar 4. Link parameter humanoid robot.

Tahapan selanjutnya adalah mengindifikasi link parameter. Berdasarkan Gambar 3 dan 4 maka dapat ditentukan DH parameter pada kaki kanan, kaki kiri, tangan kanan, dan tangan kiri yang hasilnya ditabelkan pada Tabel 3-6:

Tabel 3. DH parameter kaki kanan / right leg (RL).

\begin{tabular}{|c|c|c|c|c|}
\hline $\begin{array}{c}\text { Link } \\
\mathrm{i}\end{array}$ & $\begin{array}{c}\alpha_{\mathrm{RL}, \mathrm{i}-1} \\
{\left[{ }^{\circ}\right]}\end{array}$ & $\begin{array}{c}\mathrm{a}_{\mathrm{RL}, \mathrm{i}-1} \\
{[\mathrm{~mm}]}\end{array}$ & $\begin{array}{c}\mathrm{d}_{\mathrm{RL}, \mathrm{I}} \\
{[\mathrm{mm}]}\end{array}$ & $\left.\theta_{\mathrm{RL}, \mathrm{I}}{ }^{\circ}\right]$ \\
\hline 1 & 0 & 0 & 0 & $\theta_{\mathrm{RL} 1}$ \\
\hline 2 & -90 & 43,05 & 0 & $\theta_{\mathrm{RL} 2}$ \\
\hline 3 & 0 & 43,05 & 0 & $\theta_{\mathrm{RL} 3}$ \\
\hline 4 & 0 & 70 & 0 & $\theta_{\mathrm{RL} 4}$ \\
\hline 5 & 90 & 39 & 0 & $\theta_{\mathrm{RL} 5}$ \\
\hline
\end{tabular}

Tabel 5. DH parameter tangan kanan / right arm (RA).

\begin{tabular}{|c|c|c|c|c|}
\hline $\begin{array}{c}\text { Link } \\
\mathrm{i}\end{array}$ & $\begin{array}{c}\alpha_{\mathrm{RA}, \mathrm{i}-1} \\
{\left[{ }^{\circ}\right]}\end{array}$ & $\begin{array}{c}\mathrm{a}_{\mathrm{RA}, \mathrm{i}-1} \\
{[\mathrm{~mm}]}\end{array}$ & $\begin{array}{c}\mathrm{d}_{\mathrm{RA}, \mathrm{I}} \\
{[\mathrm{mm}]}\end{array}$ & $\theta_{\mathrm{RA}, \mathrm{I}}\left[^{\circ}\right]$ \\
\hline 1 & 0 & 0 & 0 & $\theta_{\mathrm{RA} 1}$ \\
\hline 2 & 90 & 43,05 & 0 & $\theta_{\mathrm{RA} 2}$ \\
\hline 3 & -90 & 43,05 & 0 & $\theta_{\mathrm{RA} 3}$ \\
\hline 4 & 90 & 70 & 0 & $\theta_{\mathrm{RA} 4}$ \\
\hline
\end{tabular}

Tabel 4. DH parameter kaki kiri/ left leg (LL).

\begin{tabular}{|c|c|c|c|c|}
\hline $\begin{array}{c}\text { Link } \\
\mathrm{i}\end{array}$ & $\begin{array}{c}\alpha_{\mathrm{LL}, \mathrm{i}-1} \\
{\left[{ }^{\circ}\right]}\end{array}$ & $\begin{array}{c}\mathrm{a}_{\mathrm{LL}, \mathrm{i}-1} \\
{[\mathrm{~mm}]}\end{array}$ & $\begin{array}{c}\mathrm{d}_{\mathrm{LL}, \mathrm{I}} \\
{[\mathrm{mm}]}\end{array}$ & $\begin{array}{c}\theta_{\mathrm{LL}, \mathrm{I}} \\
{\left[{ }^{\circ}\right]}\end{array}$ \\
\hline 1 & 0 & 0 & 0 & $\theta_{\text {LL1 }}$ \\
\hline 2 & -90 & 39 & 0 & $\theta_{\text {LL2 }}$ \\
\hline 3 & 0 & 70 & 0 & $\theta_{\text {LL3 }}$ \\
\hline 4 & 0 & 43,05 & 0 & $\theta_{\text {LL4 }}$ \\
\hline 5 & 90 & 43,05 & 0 & $\theta_{\text {LL5 }}$ \\
\hline
\end{tabular}

Tabel 6. DH parameter tangan kiri/ left arm (LA).

\begin{tabular}{|c|c|c|c|c|}
\hline $\begin{array}{c}\text { Link } \\
\mathrm{i}\end{array}$ & $\begin{array}{c}\alpha_{\mathrm{LA}, \mathrm{i}-1} \\
{\left[{ }^{\circ}\right]}\end{array}$ & $\begin{array}{c}\mathrm{a}_{\mathrm{LA}, \mathrm{i}-1} \\
{[\mathrm{~mm}]}\end{array}$ & $\begin{array}{c}\mathrm{d}_{\mathrm{LA}, \mathrm{I}} \\
{[\mathrm{mm}]}\end{array}$ & $\begin{array}{c}\theta_{\mathrm{LA}, \mathrm{I}} \\
{\left[{ }^{\circ}\right]}\end{array}$ \\
\hline 1 & 0 & 0 & 0 & $\theta_{\mathrm{LA} 1}$ \\
\hline 2 & -90 & 35 & 0 & $\theta_{\mathrm{LA} 2}$ \\
\hline 3 & 90 & 29,50 & 0 & $\theta_{\mathrm{LA} 3}$ \\
\hline 4 & -90 & 37,50 & 0 & $\theta_{\mathrm{LA} 4}$ \\
\hline
\end{tabular}

Matrik transformasi sangat penting dalam memodelkan robot dimana berdasarkan hasil tabel DH parameter di atas (Tabel 3-6) maka persamaan matrik transformasi dari frames $\{\mathrm{i}\}$ ke $\{\mathrm{i}-1\}$ dengan menggunakan empat parameter link $\alpha_{\mathrm{i}}, \mathrm{a}_{\mathrm{i}}, d_{\mathrm{i}}$, dan $\theta_{\mathrm{i}}$ dapat diketahui dan dinyatakan sebagai berikut:

a. Matrik transformasi kaki kanan

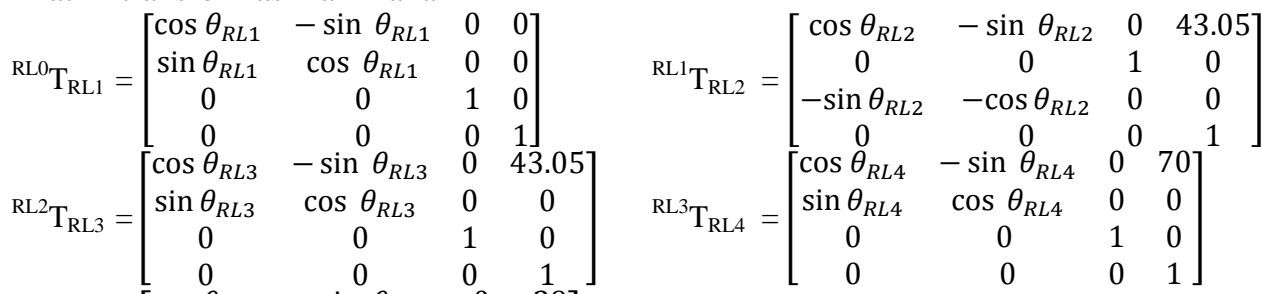

$$
\begin{aligned}
& { }^{\mathrm{RL} 4} \mathrm{~T}_{\mathrm{RL} 5}=\left[\begin{array}{cccc}
\cos \theta_{R L 5} & -\sin \theta_{R L 5} & 0 & 39 \\
0 & 0 & -1 & 0 \\
\sin \theta_{R L 5} & \cos \theta_{R L 5} & 0 & 0 \\
0 & 0 & 0 & 1
\end{array}\right]
\end{aligned}
$$

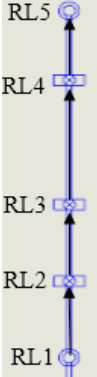

b. Matrik transformasi kaki kiri

$$
{ }^{\mathrm{RL} 5} \mathrm{~T}_{\mathrm{LL} 0}=\left[\begin{array}{cccc}
-1 & 0 & 0 & 0 \\
0 & -1 & 0 & -67.85 \\
0 & 0 & 1 & 0 \\
0 & 0 & 0 & 1
\end{array}\right]
$$

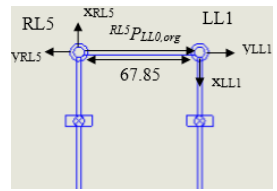




$$
\begin{aligned}
{ }^{\mathrm{LL} 0} \mathrm{~T}_{\mathrm{LL} 1} & =\left[\begin{array}{cccc}
\cos \theta_{L L 1} & -\sin \theta_{L L 1} & 0 & 0 \\
\sin \theta_{L L 1} & \cos \theta_{L L 1} & 0 & 0 \\
0 & 0 & 1 & 0 \\
0 & 0 & 0 & 1
\end{array}\right] \\
{ }^{\mathrm{LL} 1} \mathrm{~T}_{\mathrm{LL} 2} & =\left[\begin{array}{cccc}
\cos \theta_{L L 2} & -\sin \theta_{L L 2} & 0 & 39 \\
0 & 0 & 1 & 0 \\
-\sin \theta_{L L 2} & -\cos \theta_{L L 2} & 0 & 0 \\
0 & 0 & 0 & 1
\end{array}\right] \\
{ }^{\mathrm{LL} 3} \mathrm{~T}_{\mathrm{LL} 4} & =\left[\begin{array}{cccc}
\cos \theta_{L L 4} & -\sin \theta_{L L 4} & 0 & 43.05 \\
\sin \theta_{L L 4} & \cos \theta_{L L 4} & 0 & 0 \\
0 & 0 & 1 & 0 \\
0 & 0 & 0 & 1
\end{array}\right] \\
{ }^{\mathrm{LL} 2} \mathrm{~T}_{\mathrm{LL} 3} & =\left[\begin{array}{cccc}
\cos \theta_{L L 3} & -\sin \theta_{L L 3} & 0 & 70 \\
\sin \theta_{L L 3} & \cos \theta_{L L 3} & 0 & 0 \\
0 & 0 & 1 & 0 \\
0 & 0 & 0 & 1
\end{array}\right]
\end{aligned}
$$

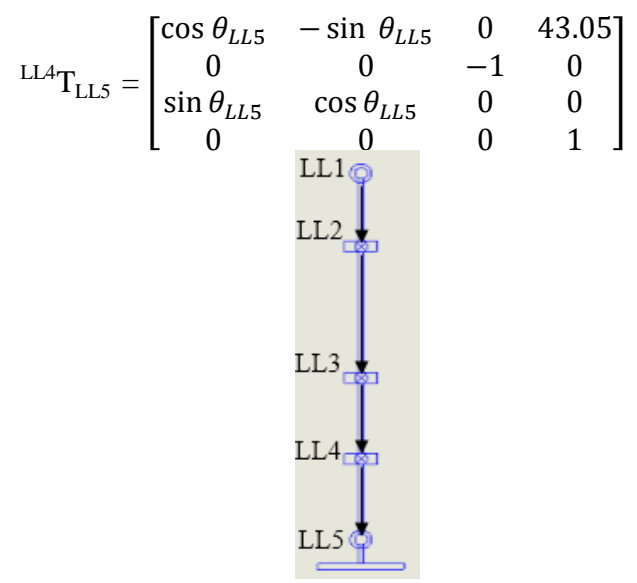

c. Matrik transformasi tangan kanan

$$
\begin{aligned}
{ }^{\mathrm{RL} 5} \mathrm{~T}_{\mathrm{RA} 0} & =\left[\begin{array}{cccc}
1 & 0 & 0 & 67.4 \\
0 & 0 & 1 & 22.5 \\
0 & -1 & 0 & 0 \\
0 & 0 & 0 & 1
\end{array}\right] \\
{ }^{\mathrm{RA} 1} \mathrm{~T}_{\mathrm{RA} 2} & =\left[\begin{array}{cccc}
\cos \theta_{R A 2} & -\sin \theta_{R A 2} & 0 & 35 \\
0 & 0 & -1 & 0 \\
\sin \theta_{R A 2} & \cos \theta_{R A 2} & 0 & 0 \\
0 & 0 & 0 & 1
\end{array}\right] \\
{ }^{\mathrm{RA} 3} \mathrm{~T}_{\mathrm{RA} 4} & =\left[\begin{array}{cccc}
\cos \theta_{R A 4} & -\sin \theta_{R A 4} & 0 & 37.5 \\
0 & 0 & -1 & 0 \\
\sin \theta_{R A 4} & \cos \theta_{R A 4} & 0 & 0 \\
0 & 0 & 0 & 1
\end{array}\right] \\
{ }^{\mathrm{RA} 0} \mathrm{~T}_{\mathrm{RA} 1} & =\left[\begin{array}{cccc}
\cos \theta_{R A 1} & -\sin \theta_{R A 1} & 0 & 0 \\
\sin \theta_{R A 1} & \cos \theta_{R A 1} & 0 & 0 \\
0 & 0 & 1 & 0 \\
0 & 0 & 0 & 1
\end{array}\right]
\end{aligned}
$$

$$
{ }^{\mathrm{RA} 2} \mathrm{~T}_{\mathrm{RA} 3}=\left[\begin{array}{cccc}
\cos \theta_{R A 3} & -\sin \theta_{R A 3} & 0 & 29.5 \\
0 & 0 & 1 & 0 \\
-\sin \theta_{R A 3} & -\cos \theta_{R A 3} & 0 & 0 \\
0 & 0 & 0 & 1
\end{array}\right]
$$

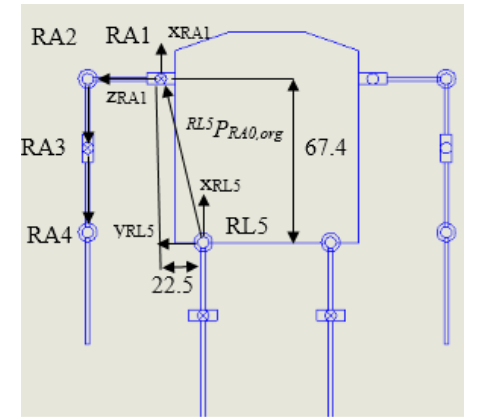

d. Matrik transformasi tangan kiri

$$
\begin{aligned}
{ }^{\mathrm{RL} 5} \mathrm{~T}_{\mathrm{LA} 0} & =\left[\begin{array}{cccc}
1 & 0 & 0 & 67.4 \\
0 & 0 & -1 & -90.35 \\
0 & 1 & 0 & 0 \\
0 & 0 & 0 & 1
\end{array}\right] \\
{ }^{\mathrm{LA} 1} \mathrm{~T}_{\mathrm{LA} 2} & =\left[\begin{array}{cccc}
\cos \theta_{L A 2} & -\sin \theta_{L A 2} & 0 & 35 \\
0 & 0 & 1 & 0 \\
-\sin \theta_{L A 2} & -\cos \theta_{L A 2} & 0 & 0 \\
0 & 0 & 0 & 1
\end{array}\right] \\
{ }^{\mathrm{LA} 3} \mathrm{~T}_{\mathrm{LA} 4} & =\left[\begin{array}{cccc}
\cos \theta_{L A 4} & -\sin \theta_{L A 4} & 0 & 37.5 \\
0 & 0 & 1 & 0 \\
-\sin \theta_{L A 4} & -\cos \theta_{L A 4} & 0 & 0 \\
0 & 0 & 0 & 1
\end{array}\right] \\
{ }^{\mathrm{LA} 0} \mathrm{~T}_{\mathrm{LA} 1} & =\left[\begin{array}{cccc}
\cos \theta_{L A 1} & -\sin \theta_{L A 1} & 0 & 0 \\
\sin \theta_{L A 1} & \cos \theta_{L A 1} & 0 & 0 \\
0 & 0 & 1 & 0 \\
0 & 0 & 0 & 1
\end{array}\right]
\end{aligned}
$$$$
{ }^{\mathrm{LA} 2} \mathrm{~T}_{\mathrm{LA} 3}=\left[\begin{array}{cccc}
\cos \theta_{L A 3} & -\sin \theta_{L A 3} & 0 & 29.5 \\
0 & 0 & -1 & 0 \\
\sin \theta_{L A 3} & \cos \theta_{L A 3} & 0 & 0 \\
0 & 0 & 0 & 1
\end{array}\right]
$$

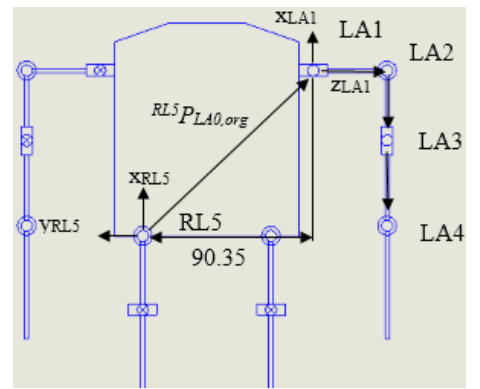

Selanjutnya untuk mendapatkan matriks transformasi dari matrik ${ }^{\mathrm{RL} 0} \mathrm{~T}_{\mathrm{RL} 1}$ sampai dengan matrik ${ }^{\mathrm{LL} 4} \mathrm{~T}_{\mathrm{LL} 5}$ yang ditunjukkan pada Gambar 5 (a) diperoleh dengan menggunakan persamaan berikut:

$$
\begin{aligned}
{ }^{\mathrm{RL} 0} \mathrm{~T}_{\mathrm{LL} 5} & ={ }^{\mathrm{RL} 0} \mathrm{~T}_{\mathrm{RL} 1}{ }^{\mathrm{RL} 1} \mathrm{~T}_{\mathrm{RL} 2}{ }^{\mathrm{RL} 2} \mathrm{~T}_{\mathrm{RL} 3}{ }^{\mathrm{RL} 3} \mathrm{~T}_{\mathrm{RL} 4}{ }^{\mathrm{RL} 4} \mathrm{~T}_{\mathrm{RL} 15}{ }^{\mathrm{RL} 5} \mathrm{~T}_{\mathrm{LL} 0}{ }^{\mathrm{LL} 0} \mathrm{~T}_{\mathrm{LL} 1}{ }^{\mathrm{LL1} 1} \mathrm{~T}_{\mathrm{LL} 2}{ }^{\mathrm{LL} 2} \mathrm{~T}_{\mathrm{LL} 3}{ }^{\mathrm{LL} 3} \mathrm{~T}_{\mathrm{LL} 4}{ }^{\mathrm{LL} 4} \mathrm{~T}_{\mathrm{LL} 5} \\
& =\left[\begin{array}{cccc}
r 11 & r 12 & r 13 & P x \\
r 21 & r 22 & r 23 & P y \\
r 31 & r 32 & r 33 & P z \\
0 & 0 & 0 & 1
\end{array}\right]
\end{aligned}
$$




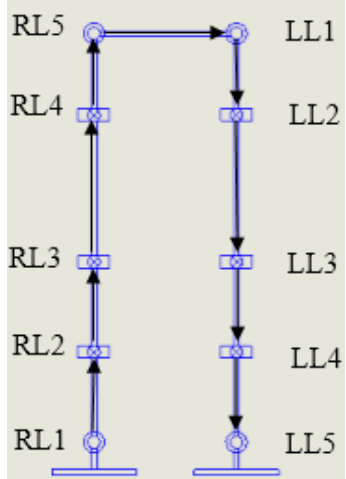

(a)

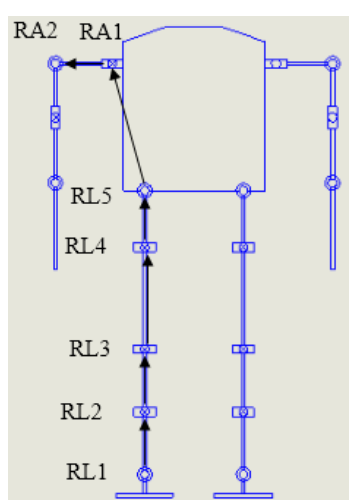

(b)

Gambar 5. Matrik transformasi dari matrik (a) ${ }^{\mathrm{RL} 0} \mathrm{~T}_{\mathrm{RL} 1}$ (joint pertama kaki kanan) sampai matrik ${ }^{\mathrm{LL} 4} \mathrm{~T}_{\mathrm{LL} 5}$ (joint kelima kaki kiri) dan (b) ${ }^{\mathrm{RL} 0} \mathrm{~T}_{\mathrm{RL} 1}$ (joint pertama kaki kanan) sampai dengan matrik ${ }^{\mathrm{RA1}} \mathrm{T}_{\mathrm{RA} 2}$ (joint kedua tangan kanan).

Dan untuk mendapatkan matriks transformasi dari matrik ${ }^{\mathrm{RL} 0} \mathrm{~T}_{\mathrm{RL} 1}$ sampai dengan matrik ${ }^{\mathrm{LA} 1} \mathrm{~T}_{\mathrm{LA} 2}$ yang ditunjukkan pada Gambar 5 (b) nytakan dalam persamaan berikut:

$$
\begin{aligned}
{ }^{\mathrm{RL} 0} \mathrm{~T}_{\mathrm{LA} 3} & ={ }^{\mathrm{RL} 0} \mathrm{~T}_{\mathrm{RL} 1}{ }^{\mathrm{RL} 1} \mathrm{~T}_{\mathrm{RL}}{ }^{\mathrm{RL} 2} \mathrm{~T}_{\mathrm{RL} 3}{ }^{\mathrm{RL} 3} \mathrm{~T}_{\mathrm{RL} 4}{ }^{\mathrm{RL} 4} \mathrm{~T}_{\mathrm{RL} 15}{ }^{\mathrm{RL} 5} \mathrm{~T}_{\mathrm{LA} 0}{ }^{\mathrm{LA} 0} \mathrm{~T}_{\mathrm{LA} 1}{ }^{\mathrm{LA} 1} \mathrm{~T}_{\mathrm{LA} 2} \\
& =\left[\begin{array}{cccc}
r 11 & r 12 & r 13 & P x \\
r 21 & r 22 & r 23 & P y \\
r 31 & r 32 & r 33 & P z \\
0 & 0 & 0 & 1
\end{array}\right]
\end{aligned}
$$

\subsection{Pemodelan Dinamik}

Dalam pergerakan humanoid robot, akan dilihat dari dua bidang (planes) yaitu bidang pergerakan depan (frontal plane) dan bidang pergerakan samping (sagittal plane). Dalam pergerakan pada frontal plane, aktuator yang bekerja adalah aktuator pada joint pertama dan joint kelima kaki kanan $\left(\theta_{R L 1}\right.$ dan $\left.\theta_{R L 5}\right)$ serta joint pertama dan kelima kaki kiri $\left(\theta_{L L 1}\right.$ dan $\left.\theta_{L L 5}\right)$, sedangkan aktuator pada joint yang lain tidak bekerja atau pasif karena aktuator pada joint tersebut bekerja pada sagital plane. Posisi pergerakan pada frontal plane ditunjukan pada Gambar 6.

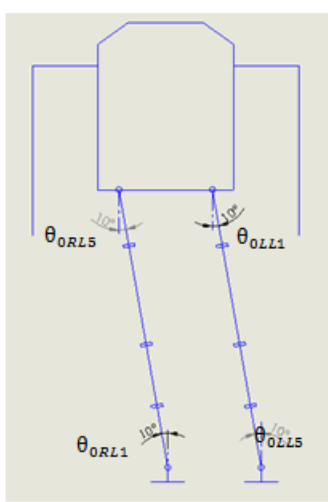

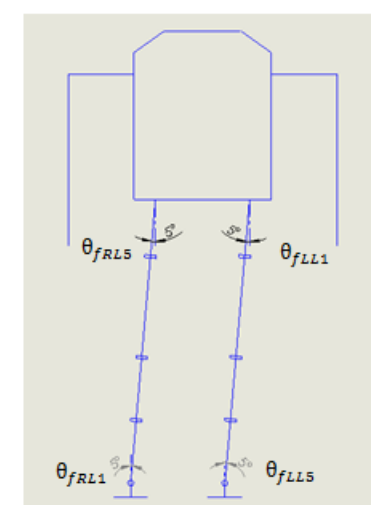

(b)

Gambar 6. Pergerakan pada frontal plane untuk posisi awal (a) dan posisi akhir (b).

Selanjutnya berdasarkan trajectory dengan menggunakan persamaan polynomial orde tiga didapat posisi sudut dan kecepatan sudut terhadap waktu yang ditunjukan di grafik pada Gambar 7 dan Gambar 8.

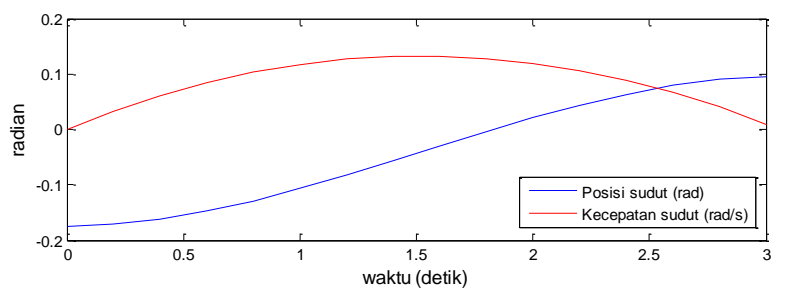

Gambar 7. Grafik posisi sudut dan kecepatan sudut pada $\theta_{R L 1}$ dan $\theta_{L L 5}$.

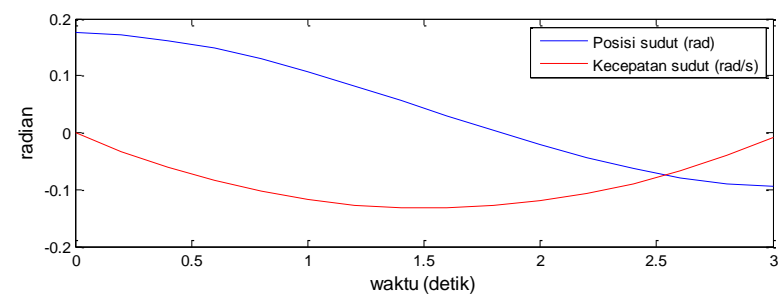

Gambar 8. Grafik posisi sudut dan kecepatan sudut pada $\theta_{R L 5}$ dan $\theta_{L L 1}$. 
Dengan menganalisa pergerakan humanoid robot pada bidang depan (frontal plane) seperti yang ditunjukkan pada Gambar 6, yaitu dengan memisalkan sudut aktuator $\theta_{0 R L 1}=\theta_{0 L L 5}$ adalah sebesar $-10^{\circ}$ dan $\theta_{f R L 5}=\theta_{f L L 1}$ sebesar $5^{\circ}$, maka torsi pada joint ankle kaki kanan $\left(\tau_{R L 1}\right)$ yang bekerja saat pergerakan pada frontal plane dengan menggunakan persamaan Lagrangian akan diperoleh nilai torsi seperti yang ditunjukan pada Gambar 9.

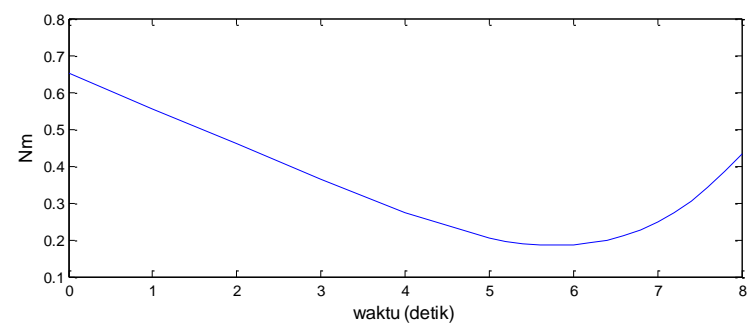

Gambar 9. Torsi joint ankle $\left(\tau_{R L 1}\right)$ yang bekerja atas pergerakan pada frontal plane.

Selanjutnya untuk pergerakan sagittal plane, aktuator yang bekerja adalah aktuator pada joint kedua, joint ketiga dan joint keempat kaki kanan dan kaki kiri $\left(\theta_{R L 2}, \theta_{R L 3}, \theta_{R L 4}\right.$ dan $\left.\theta_{L L 2}, \theta_{L L 3}, \theta_{L L 4}\right)$ serta pada joint pertama tangan kanan dan tangan kiri $\left(\theta_{R A 1}\right.$ dan $\left.\theta_{L A 1}\right)$. Posisi sudut aktuator humanoid robot pada sagittal plane ditunjukan pada Gambar 10.

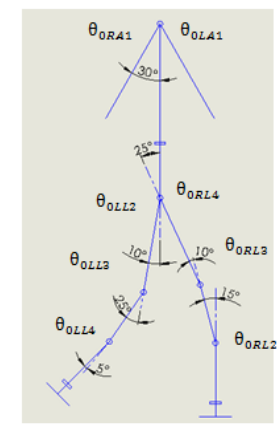

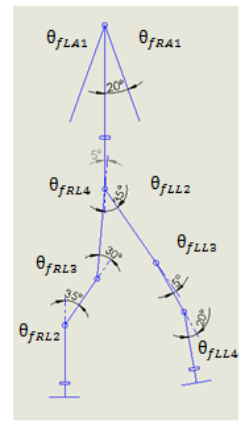

(b)

Gambar 10. Pergerakan pada sagittal plane untuk posisi awal (a) dan posisi akhir (b).

Berdasarkan Gambar 10, dengan diketahui nilai variabel sudut-sudut aktuator humanoid robot pada saat awal melangkah dan akhir melangkah, maka dapat diketahui trajectory pada tiap joint dengan persamaan polynomial orde tiga. Trajectory pada joint kedua kaki kanan $\left(\theta_{R L 2}\right)$ dan joint ketiga kaki kanan $\left(\theta_{R L 3}\right)$ masing-masing ditunjukan di grafik pada Gambar 11 (a) dan 11 (b).

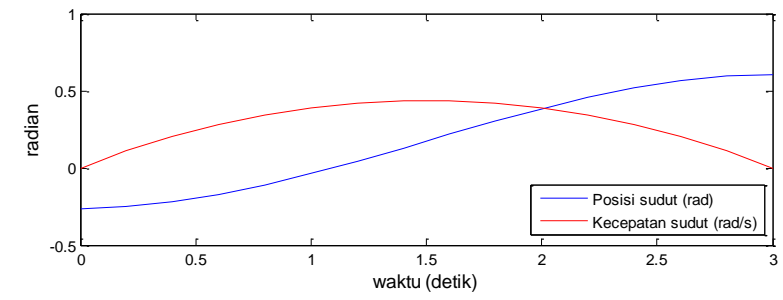

(a)

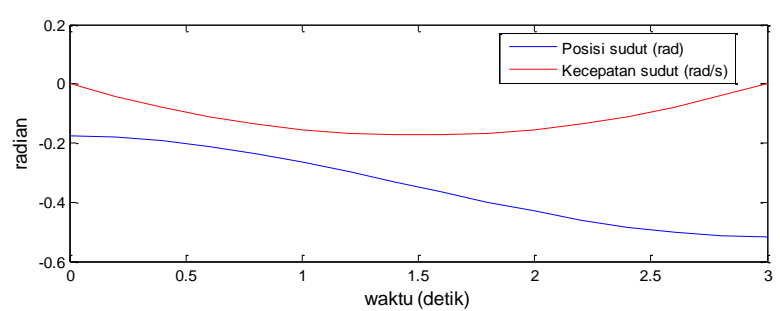

(b)

Gambar 11. Grafik posisi sudut dan kecepatan sudut pada $\theta_{R L 2}$ (a) dan $\theta_{R L 3}$ (b)

Selanjutnya, trajectory pada joint keempat kaki kanan $\left(\theta_{R L 4}\right)$ dan kedua kaki kiri $\left(\theta_{L L 2}\right)$ secara berurutan ditunjukkan pada Gambar 12 (a) dan 12 (b). Untuk trajectory pada joint kedua kaki kiri $\left(\theta_{L L 3}\right)$ dan kedua kaki kiri $\left(\theta_{L L 4}\right)$ masingmasing ditunjukkan pada Gambar 13 (a) dan 13 (b).

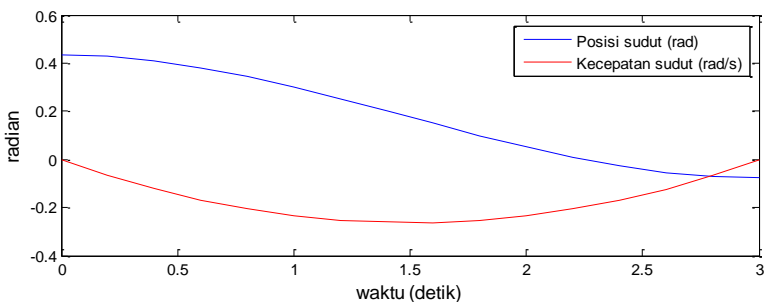

(a)

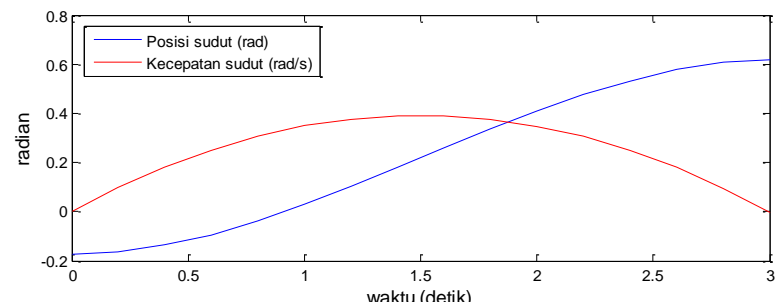

(b)

Gambar 12. Grafik posisi sudut dan kecepatan sudut pada $\theta_{R L 4}$ (a) dan $\theta_{L L 2}$ (b) 


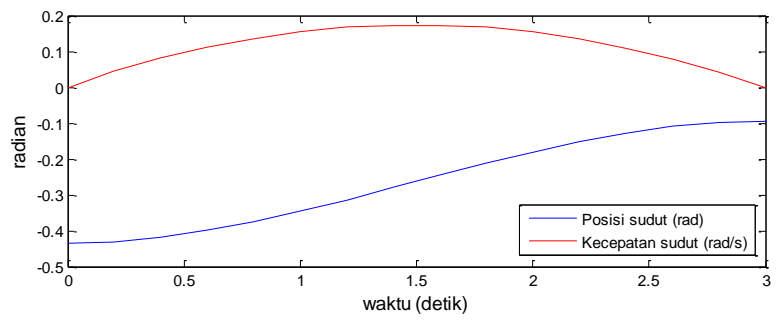

(a)

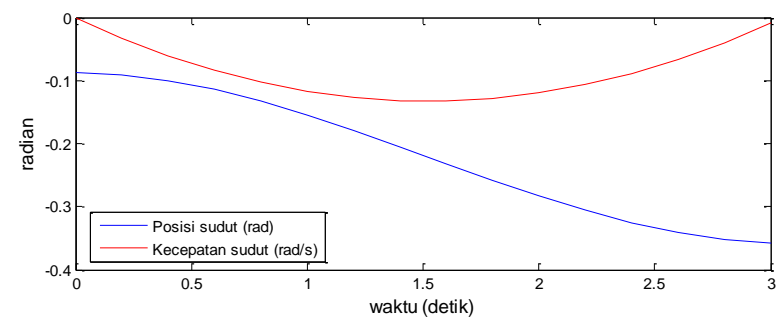

(b)

Gambar 13. Grafik posisi sudut dan kecepatan sudut pada $\theta_{L L 3}$ (a) dan $\theta_{L L 4}$ (b)

Adapun trajectory pada joint kedua kaki kiri $\left(\theta_{R A 1}\right)$ dan kedua kaki kiri $\left(\theta_{L A 1}\right)$ masing-masing ditunjukkan pada Gambar 14 (a) dan 14 (b).

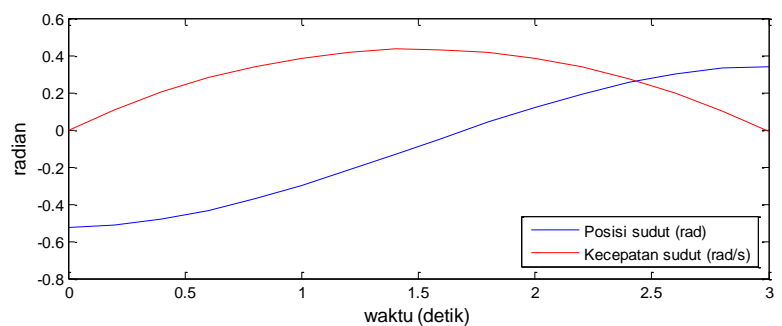

(a)

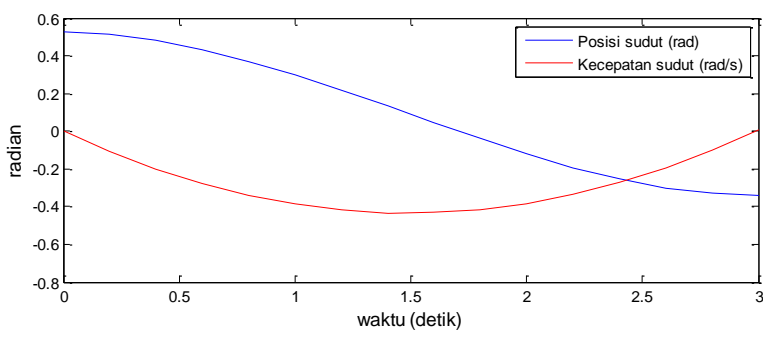

(b)

Gambar 14. Grafik posisi sudut dan kecepatan sudut pada $\theta_{R A 1}$ (a) dan $\theta_{\text {LA1 }}$ (b).

\section{KESIMPULAN}

Pada penelitian yang berkenaan dengan humanoid robot ini, penulis berhasil mendesain kontruksi mekanik humanoid robot yang sederhana, dan direncanakan menggunkan bahan acrylic dan almunium sehingga murah dan ringan. Desain humanoid robot selanjutnya dimodelkan berdasarkan kinematik dan dinamiknya. Pemodelan kinematik pada humanoid robot meliputi tahapan menentukan frames link robot, mengidentifikasi parameter 4 link pada setiap link robot, dan menghitung hubungan matrik transformasinya. dalam pemodelan dinamik telah menggunakan persamaan Lagrangian, sehingga berhasil diperoleh torsi pada joint ankle pada kaki kanan humanoid robot dan trajectory aktuator pada tiap joint humanoid robot.

\section{REFERENSI}

[1] Ray Asfahl, 1992, "Robot and Manufacturing Automation," John Wiley \& Sons, $2^{\text {nd }}$ Edition.

[2] Moh. Imam Afandi, "Pemodelan Kinematika Sistem Pengarahan Misil dengan Perhitungan Gangguan pada Landasa," LIPI Tanggerang.

[3] Bajers Fredrik, 2007, "Modelling and Control of a Biped Robot," Department of Control Engineering $8^{\text {th }}$ Semester Aalborg University.

[4] Craig, J. J., 2003, “Introduction to Robotics Mechanics and Control," Pearson Prentice Hall, $2^{\text {nd }}$ Edition. 